\section{DR5 unfolds ER stress}

\begin{tabular}{|c|c|}
\hline $\begin{array}{l}\text { DR5 integrates } \\
\text { opposing } \\
\text { UPR signals } \\
\text { to control } \\
\text { ER-stress- } \\
\text { induced } \\
\text { apoptosis }\end{array}$ & $\begin{array}{l}\text { Endoplasmic reticulum (ER) stress } \\
\text { caused by the accumulation of } \\
\text { unfolded proteins in the ER lumen } \\
\text { activates the unfolded protein } \\
\text { response (UPR) to control the } \\
\text { protein-folding capacity of the orga- } \\
\text { nelle. When ER stress is unmitigated, } \\
\text { the UPR activates apoptosis through } \\
\text { the interplay of two key mediators, } \\
\text { protein kinase R-like kinase (PERK) } \\
\text { and inositol-requiring enzyme 1a } \\
\text { (IRE1a); however, the mechanisms } \\
\text { regulating apoptosis initiation } \\
\text { were unclear. Lu et al. now show } \\
\text { that ER-stress-induced apoptosis is } \\
\text { controlled by death receptor } 5 \text { (DR5) } \\
\text { and that DR5 levels are regulated } \\
\text { by the opposing activities of PERK } \\
\text { and IRE1 } \text {. }\end{array}$ \\
\hline
\end{tabular}

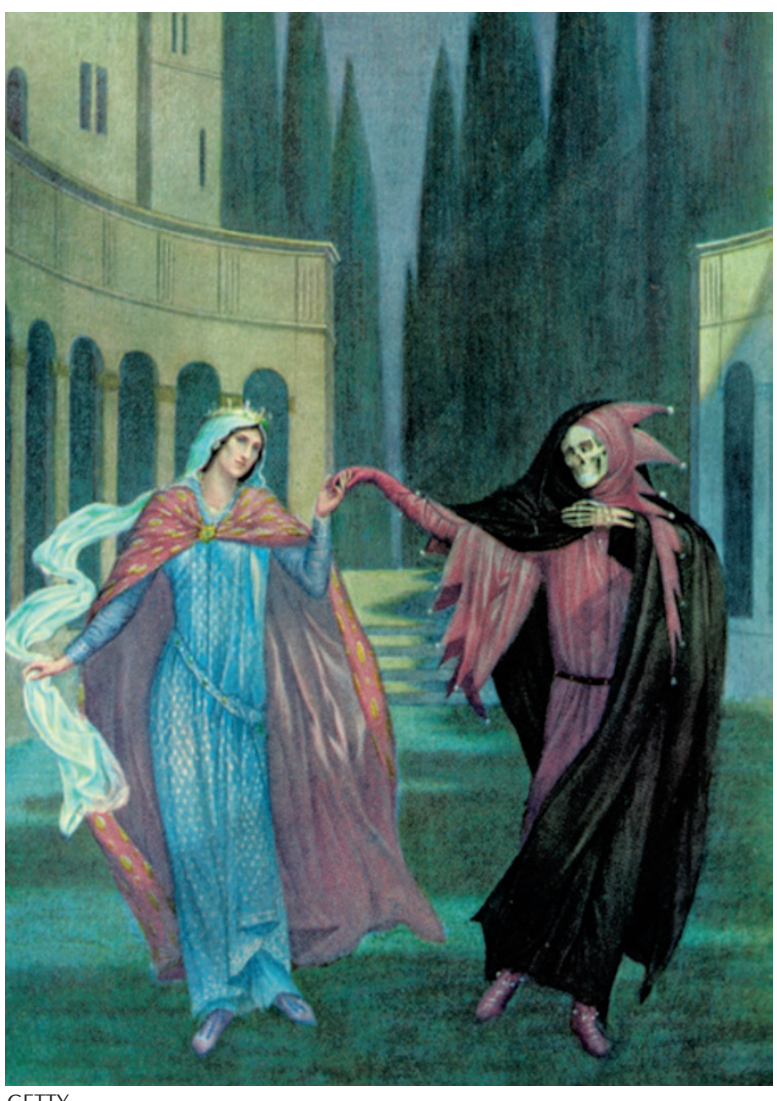

GETTY
The authors observed that the treatment of human cell lines with various ER stressors, such as the ER calcium pump inhibitor thapsigargin, led to apoptosis through the activation of caspase 8 , the initiator caspase downstream of the death receptor pathway. Next, the authors examined which of the death receptors activates caspase 8 in response to ER stress. They found that several ER stressors induced DR5 expression and that these stressors had much less impact on other death receptors. Furthermore, ER stress induced the formation of the caspase 8-activating complex, comprising caspase 8 , DR5 and the caspase 8 adaptor Fasassociated death domain (FADD). Importantly, activation of DR5 occurred intracellularly and independently of its extracellular ligand TNFrelated apoptosis-inducing ligand (TRAIL; also known as APO2L). Moreover, DR5 depletion strongly inhibited both caspase activation and apoptosis. These results suggest that DR5 is crucial for caspase 8-mediated apoptosis in response to ER stress.

The transcription factors C/EBP homologous protein (CHOP) and spliced X-box-binding protein 1 (XBP1s) are major effectors of PERK and IRE1a, respectively. The authors found that ER stressors induced persistent expression of CHOP and transient expression of XBP1s.
Depletion of CHOP blocked the upregulation of DR 5 mRNA by ER stressors, whereas knockdown of the transcriptional targets of $\mathrm{CHOP}$ did not, which indicated that $\mathrm{CHOP}$ controls DR5 mRNA accumulation directly. By contrast, IRE1 $a$ mediated DR5 mRNA decay, and IRE1 $\alpha$ depletion or inhibition accentuated ER-stress-induced DR5 upregulation, caspase 8 activation and apoptosis. Interestingly, XBP1s depletion accelerated DR5 mRNA decay and decreased apoptosis. These results suggest that IRE1 a counteracts PERK-mediated apoptosis by directly decreasing DR5 transcript levels.

In summary, DR5 integrates opposing UPR signals to control ER-stress-induced apoptosis: PERK-CHOP activity induces DR5 transcription, whereas IRE1a promotes DR5 mRNA decay. Thus, DR5 levels are a measure of the persistence of ER stress, and are controlled by the opposing activities of PERK and IRE $1 \alpha$ to define a time window for adaptation to ER stress before committing cells to apoptosis.

\section{Eytan Zlotorynski}

ORIGINAL RESEARCH PAPER Lu, M. et al.

Opposing unfolded-protein-response signals converge on death receptor 5 to control apoptosis. Science 345, 98-101 (2014) FURTHER READING Hetz, C. The unfolded protein response: controlling cell fate decisions under ER stress and beyond. Nature Rev. Mol. Cell Biol. 13, 89-102 (2012) 